\title{
Using Junyi Academy to Explore the Difference in Learning Attitude of Remedial Instruction
}

\author{
Yi -Hsueh Shen ${ }^{(1)}$, Chen-Feng Wu ${ }^{(2)}$, Li-Hua Liu(3) \\ (1) Jen-teh Junior College of Medicine, Nursing and Management, Taiwan. \\ ian343.sdk@msa.hinet.net \\ ${ }^{2}$ Yu Da University of Science and Technology, Taiwan. \\ cfwu@ydu.edu.tw \\ (3)Yu Da University of Science and Technology, Taiwan. \\ lihua@gmail.com
}

\begin{abstract}
As the concept of digital learning becomes increasingly clear, so does the labor division of instruction. The teachers who specialize in teaching no longer have to spare efforts to focus on something beyond instruction, which has led to the invention of instruction platforms. This study aims to probe into the difference in learning attitude among the students of the remedial instruction based on Junyi Academy. In this study, Junyi Academy was integrated with the remedial instruction of mathematics. Featuring "replicable", "customized" and "adaptive", this platform was employed to provide students with another learning method in the remedial instruction. The quasi-experiment method was adopted; the technology acceptance model (TAM) was taken as the theoretical foundation of the research structure; the behavioral scale which combined Junyi Academy with the remedial instruction of mathematics was used as the research tool; 26 freshmen of a junior college in Miaoli County were taken as the samples. Through the experimental instruction, this study discussed the students' acceptance of the remedial instruction based on Junyi Academy. One of the research purposes is that students will be able to study online by linking their computers with Junyi Academy and will not be confined to the learning time and place designated by schools. Another research purpose is to demonstrate that Junyi Academy is feasible for the remedial instruction.
\end{abstract}

\section{Keywords}

Remedial instruction, Junyi Academy, technology acceptance model

\section{INTRODUCTION}

The teachers of the traditional remedial instruction tend to use the same teaching materials or instruction methods; as a result, the students who academically lag behind would not be able to adapt to such a standard instruction. With the passage of time, these students will feel helpless in study. Worse still, remedial instruction costs much manpower in the process of instruction. This demonstrates that effective remedial instruction entails much time and energy.

With the popularization of the Internet, the technical advancement, and the continual technological development, a variety of learning websites with diverse contents have been established. Aside from meeting the visual demands of students, the websites are expected to satisfy their needs in study. As the concept of digital learning becomes increasingly clear, so does the labor division of instruction. The teachers who specialize in teaching no longer have to spare efforts to focus on something beyond instruction, which has led to the invention of instruction platforms. If the instruction platforms and the "replicable", "customized" and "adaptive" computer-based multimedia are utilized to provide students another learning method in the remedial instruction and trigger their learning motivation, the results may be more beneficial. This is what this study aims to discuss.

According to the findings of this study, flipped classroom is the most popular educational topic in recent years, and Junyi Academy can be used to facilitate instruction. This platform provides students with many resources for self-learning and practice and is supported by teachers' control over permission; in this way, teachers will be able to immediately get acquainted with the learning of students and the problems confronting students. If students are able to voluntarily study at home and review what puzzles them to achieve a customized and adaptive study, they will have a more flexible study schedule and save the extra time for the remedial instruction at school. Moreover, the computer-based learning will enhance their interest in learning. All these advantages cannot be seen in the traditional lecture-based instruction at school.

\section{LITERATURE REVIEW}

This study aims to incorporate Junyi Academy into the remedial instruction of mathematics and probes to the instruction process of teachers and the troubles they face in the remedial instruction of "Scientific Signs".

\section{Remedial Instruction}

In general, academic underperformance in remedial instruction is defined as follows: the last $25 \%$ of students in a class in a subject in a metropolitan area and the last 35\% in a non-metropolitan area. According to Lin (1997), remedial instruction comprised pre-test, instruction and post-test; in other words, it was in fact the cycle of evaluation, instruction and reevaluation: before the instruction, a test was conducted to find out the academic difference among students and then determine the instruction contents and teaching materials; after the instruction, the test would be conducted again to assess the students' learning effectiveness; for the students with low learning effectiveness and academic 
underperformance, the instruction would be improved according to the academic problems. This is the so-called remedial instruction. Then, the test would be conducted for the third time to evaluate the learning effectiveness. According to Tsai (2012), remedial instruction, in essence, could also be regarded as a part of instruction, but this instruction measure was the specific practice based in the difference among students; it could also be interpreted as the implementation of the "adaptive education" program.

\section{Online Instruction}

According to Khan (1997), the limitation on bandwidth affected the time of transmission and downloading of videos and pictures, which would frustrate learners and force them to give up learning. But Spitzer and Wedding (1995) believed that triggering students' learning motivation and setting the objectives of self-oriented learning could motivate students to study and share knowledge. Hence, if we want to offer a non-simultaneous online course, the problems of applying technologies to the course, as were mentioned by the above scholars, will be what must be considered and overcome.

\section{Junyi Academy}

In 2012, inspired by Khan Academy in the US, Chengzhi Educational Fund established the non-profit website -- Junyi Academy. Initially, the online mathematical questions and instruction videos of Khan Academy were cited. But to meet the educational needs of Taiwan, Junyi Academy began to record local courses and make local online exercises. The increasing instruction videos of Junyi Academy cover wide range of subjects, including mathematics (from primary to senior high schools), science (biology, physics and chemistry for senior high school students), society (citizenship and geography for junior high school students), art and humanity (including music), classic courses (calculus and English vocabulary and grammar for senior high school students), and computer science. From October 2012 when it was officially launched to April 2016, over 8,500 free learning videos were recorded, and the total number of registered users was more than 367,000 .

\section{Learning Portfolio}

In 1991, Paulson \& Mayer defined learning portfolio as the targeted collection of the effort, progress and achievement of a student in one or more areas. Sharp (1997) believed that learning portfolio was not only the collection of homework but also multidimensional analysis and thinking. Thanks to the development of the Internet, learning portfolio has become increasingly electronic. As this study adopted Junyi Academy to direct students in the online remedial instruction, the learning portfolio was an electronic one. According to Sanders (2000), online learning portfolio was not only used as an assessment tool but also a tool for learners to make plans and acquire knowledge.

\section{Technology Acceptance Model}

Based on the Theory of Reasoned Action (TRA) and Theory of Planned Behavior (TPB), Davis (1989) modified the theoretical model of Technology Acceptance Model (TAM) to meet the application situation of the information system. Its main purpose is to analyze the faith, attitude, behavioral intention and influence of technology users. Malhotra, Y., D. F. Galletta (1999) proposed that the TAM structure included 6 dimensions, including "Perceived Usefulness", "Perceived Ease of Use", "Attitude Toward Using", "Behavioral Intention to Use", "Actual System Use" and "External Variables".

\section{RESEARCH METHOD}

In this chapter, emphasis is placed on Research Design, Research Process and Data Processing and Analysis

\section{Research Design}

In this study, the freshmen of a junior college in Miaoli County were taken as the subjects. In the process, 26 students in a class, who ranked low in terms of mathematical performance, received the "remedial instruction which integrated Junyi Academy with mathematics". The Experiment Group needed to take a pre-test by filling the Behavioral Scale of Remedial Instruction Which Integrated Junyi Academy with Mathematics; then, it received the remedial instruction based on Junyi Academy; after the instruction, it took the post-test by filling the behavioral scale again.

\section{Research Process}

The research tool adopted in this study was the Behavioral Scale of Remedial Instruction Which Integrated Junyi Academy with Mathematics. Based on the TAM, this behavioral scale was adapted according to the questionnaires by Loyd and Gressard and Davis et al. in 1989 and the studies by Huang (2011), Liu (2014) and Wu (2015). It consists of 5 dimensions, namely, "Perceived Usefulness", "Perceived Ease of Use", "Attitude toward Using", "Behavioral Intention to Use" and "After-class Learning". Eighty-one students of a junior college in Miaoli County who didn't participated in the experiment took the pre-test; then, the question items were modified according to the item analysis; finally, the factor analysis was made to establish the construct validity of the scale, and the reliability analysis was made to test the reliability of the scale. The analysis of the results of the pre-test questionnaire was as follows:

\section{(1)Item Analysis:}

In the item analysis of the scale, two methods -- the critical ration and the homogeneity of variance test were adopted to test the items which were ineffective in differentiation. Normally, the standard value of CR was set as " 3.00 ". If the CR of an item was lower than "3.00", it indicated that this item was ineffective in differentiation and thus could be removed; if the CR was higher than " 3.00 ", it indicated that this item was effective in differentiation and thus could be kept. Meanwhile, the 
homogeneity of variance test was employed to obtain the total score of the scale and the product moment correlation. The product moment correlation of an item was lower than "0.4", it indicated that this item was not highly homogeneous with the whole scale and thus could be removed; if the product moment correlation was higher than " 0.4 ", it indicated that this item was highly homogeneous with the whole scale and thus could be kept. After the item analysis, 4 items failed to pass the test, including Items $15,20,21$ and 22 . Their significance probability value $(p<0.05)$ was at the significant level, but their CR values $(2.20,0.98,2.76$ and 2.09 respectively) were lower than "3.00", and their product moment correlations $(0.26,0.08,0.27$ and 0.21 respectively) were lower than " 0.4 ". Therefore, these four items were removed. The CRs and product moment correlations of the remaining items were all above the significant level and were thus kept.

\section{(2)Factor Analysis:}

To test the construct validity of the scale, the factor analysis was made after the item analysis. The scale originally had 32 items. In the item analysis, four items were removed. Hence, the remaining 28 items were used for the factor analysis. Whether this scale was suitable for the factor analysis was evaluated with the Kaiser-Meyer-Olkin (KMO) measure of sampling adequacy and the Bartlett's test of sphericity. KMO is the sampling adequacy which ranges from " 0 " to " 1 ". If $\mathrm{KMO}$ is lower than " 0.60 ", it indicates that the item variables are not suitable for the factor analysis; if the KMO of all item variables is higher than " 0.80 ", it implies that the relevance among the item variables is adequate and that the item variables are suitable for the factor analysis; if the KMO of all item variables is higher than "0.90", it means that the relevance among the item variables is highly adequate and that the item variables are highly suitable for the factor analysis. The KMO of this study was " 0.856 " and was at the adequate level; its chi-square value of Bartlett's test of sphericity was " 1580.316 "; its DOF was " 378 " and significance probability value was $p=0.000$ (significant). This demonstrated that the items of the scale shared factors and that the factor analysis could be made.

Table 1. KMO and Bartlett's Test of Sphericity

\begin{tabular}{|c|c|c|}
\hline Kaiser-Meyer-Olkin Measure of Sampling Adequacy & & $\mathbf{0 . 8 5 6}$ \\
\hline Bartlett's Test of Sphericity & $\begin{array}{c}\text { Appropriate chi-square } \\
\text { distribution }\end{array}$ & 1580.316 \\
\cline { 3 - 3 } & $\begin{array}{l}\text { Degree of freedom } \\
\text { Significance }\end{array}$ & 378 \\
\cline { 3 - 3 } & Sign \\
\hline
\end{tabular}

In this study, the principal component analysis was adopted to estimate factor loadings. Indicating the correlation between variables and factors, factor loadings stay between "-1" and "1". According to the report of Hair, Black, Babin, Anderson \&Tatham (2006) on the simulation results of BMDP Statistics Software Company, a factor loading lower than "0.4" was too low while the one higher than " 0.6 " was high. Therefore, this study set the factor loadings CR of this scale as " 0.5 ". Hence, if the factor loading was lower than "0.5", it indicated that the item was highly unsatisfactory and that the variable of the item could not effectively reflect its common factor; hence, the item could be removed. In the factor analysis, Harman, Harry Horace proposed in 1976 that empirically feature value should not be lower than "1". If a feature value is lower than "1", it indicates that the factor analysis has less than one variable. Therefore, the feature values of the principal component analysis are expected to be higher than " 1 ".

The factor analysis of this scale was conducted with the above factor loading being higher than " 0.5 " and the feature value being higher than " 1 ". The results showed that the factor loading of Item 7 was "0.472" (which was lower than "0.5") and was thus removed. All the remaining items met the reference standards.

\section{(3) Reliability Analysis:}

In this study, Cronbach value was taken as the evaluation standard of the questionnaire reliability to measure the consistency and stability among the items of the questionnaire. A higher value indicated that the scale was more stable, and a higher level of consistency indicated stronger consistency among the items. In 1978, Nunnally proposed the rules of evaluating reliability value of a scale and suggested that the " $\alpha$ " ranging from " 0.65 " to " 0.70 " was the accepted minimum. The Cronbach value of the total behavioral scale of this study was "0.949", indicating a high level of reliability. The Cronbach values of other dimensions were all higher than " 0.800 ", indicating "reliable".

After the item analysis, the factor analysis and the reliability analysis, Items 7, 15, 20, 21 and 22 were removed, and the 27 remaining ones were kept. Then, the experts and several senior teachers of the junior college were invited to make the final modification and the Behavioral Scale of Remedial Instruction Which Integrated Junyi Academy with Mathematics was finalized. All the item numbers were reset in the pre-test and the post-test.

\section{Data Processing and Analysis}

In this study, the Behavioral Scale of Remedial Instruction Which Integrated Junyi Academy with Mathematics was adopted for the experimental instruction. The data obtained in the pre-test and the post-test were processed, and the invalid questionnaires were removed. The following statistical analyses were made:

(1)Descriptive statistics: The basic statistical data were presented through such descriptive statistics as mean and standard error.

(2)Paired sample T-test: The paired sample T-test was adopted to analyze the difference in the attitude toward computer and in after-class learning among the students of the Experimental Group before and after they adopted Junyi Academy for the remedial instruction. 
(3)Pearson product moment correlation: the product moment correlation analysis was made to discuss the correlation and direction among the variables. The scores the students of the Experimental Group obtained in the Behavioral Scale of Remedial Instruction Which Integrated Junyi Academy with Mathematics and the total time the students of the Experimental Group spent on Junyi Academy-based remedial instruction were used for the correlation analysis.

\section{RESULTS AND DISCUSSION}

The original number of the copies of the Behavioral Scale of Remedial Instruction Which Integrated Junyi Academy with Mathematics for the Experimental Group was 26. After the process, it was found that all of the 26 copies were valid ones.

Table 2. Benchmarks of Attitude towards the Behavioral Scale of Remedial Instruction Which Integrated Junyi Academy with Mathematics

\begin{tabular}{|c|c|c|c|c|c|c|}
\hline \multirow[b]{2}{*}{ Dimension } & \multirow[b]{2}{*}{$\begin{array}{l}\text { Number } \\
\text { of Item }\end{array}$} & \multirow{2}{*}{$\begin{array}{c}\text { Mean of } \\
\text { Benchmarks } \\
\text { Evaluation of } \\
\text { Positive and } \\
\text { Negative } \\
\text { Attitudes }\end{array}$} & \multicolumn{2}{|c|}{ Pre-test } & \multicolumn{2}{|c|}{ Post-test } \\
\hline & & & Average mean & $\begin{array}{l}\text { Standard } \\
\text { deviation }\end{array}$ & $\begin{array}{c}\text { Average } \\
\text { mean }\end{array}$ & $\begin{array}{l}\text { Standard } \\
\text { deviation }\end{array}$ \\
\hline Perceived Usefulness & 6 & 18 & 23.692 & 2.926 & 28.231 & 1.423 \\
\hline Perceived Ease of & 3 & 9 & 11.462 & 1.941 & 13.231 & 1.423 \\
\hline $\begin{array}{c}\text { Attitude Toward } \\
\text { Using }\end{array}$ & 8 & 24 & 30.538 & 4.215 & 35.692 & 2.469 \\
\hline $\begin{array}{c}\text { Behavioral Intention } \\
\text { to Use }\end{array}$ & 5 & 15 & 18.769 & 2.242 & 21.692 & 1.750 \\
\hline After-class learning & 5 & 15 & 18.923 & 2.431 & 21.923 & 1.891 \\
\hline $\begin{array}{c}\text { Total Attitude Toward } \\
\text { Using }\end{array}$ & 27 & 81 & 103.385 & 11.229 & 183.077 & 19.927 \\
\hline
\end{tabular}

In this study, the Likert 5-point scale was adopted for the scoring. The score for each item ranged from " 1 " to " 5 ", so the mean " 3 " was taken as the evaluation benchmark of positive and negative attitudes. Then, the mean was multiplied with the number of items of all dimensions. The product would be taken as the evaluation value of positive and negatives attitudes. The statistics are shown in Table 2. As the Experimental Group took the pre-test and the post-test, the paired sample T-test was adopted for the data analysis. If the significance probability value was $p=0.05$, indicating insignificant, it means that there was no significant difference between the score of the pre-test and that of the post-test; if the significance probability value was $p \leqq 0.05$, indicating significant, it means that there was significant difference between the two.

The analysis of the paired sample T-test results of the pre-test and the post-test based on the Behavioral Scale of Remedial Instruction Which Integrated Junyi Academy with Mathematics is as follows:

(1)Difference in "Attitude Toward Using" before and after the instruction:

The significance probability value "p" was "0.002", indicating a significant level. This demonstrates that there was significant difference in "Attitude toward Using" before and after the remedial instruction based on Junyi Academy among the students of the Experimental Group. The average of "Attitude toward Using" after the instruction was higher than that before the instruction. The details are shown in Table 3.

Table 3. Paired Sample T-Test on "Attitude toward Using" of the Behavioral Scale of Junyi Academy

\begin{tabular}{|c|c|c|c|c|c|c|c|c|}
\hline Post-test on & & Differenc & in Paired & 'ariables & & & & \\
\hline Using & & & $\begin{array}{c}\text { Standard } \\
\text { Error of }\end{array}$ & $\begin{array}{r}95 \% \\
\text { Interval }\end{array}$ & $\begin{array}{l}\text { nfidence } \\
\text { Difference }\end{array}$ & $\mathbf{t}$ & DOF & (two- \\
\hline Pre-test on & mean & deviation & Mean & $\begin{array}{c}\text { Lower } \\
\text { Limit }\end{array}$ & Upper Limit & & & \\
\hline $\begin{array}{c}\text { Attitude Toward } \\
\text { Using }\end{array}$ & 5.154 & 4.862 & 1.349 & 2.216 & 8.092 & 3.822 & 12 & 0.002 \\
\hline
\end{tabular}

(2)Difference in "After-class Learning" before and after the instruction:

The paired sample T-test was adopted to test the variables in the pre-test and the post-test on "After-class Learning". The significance probability value "p" was "0.003", indicating a significant level. This demonstrates that there was significant difference in "After-class Learning" before and after the remedial instruction based on Junyi Academy among the students of the Experimental Group. The average of "After-class Learning" after the instruction was higher than that before the instruction. The details are shown in Table 4. 
Table 4. Paired Sample T-Test on “After-class Learning” of the Behavioral Scale of Junyi Academy

\begin{tabular}{|c|c|c|c|c|c|c|c|c|}
\hline \multirow{2}{*}{$\begin{array}{c}\text { Post-test on } \\
\text { Attitude Toward } \\
\text { Using }\end{array}$} & \multicolumn{5}{|c|}{ Difference in Paired Variables } & \multirow{3}{*}{$\mathrm{t}$} & \multirow{3}{*}{ DOF } & \multirow{3}{*}{$\begin{array}{l}\text { Sig. } \\
\text { (two- } \\
\text { tailed) }\end{array}$} \\
\hline & \multirow{2}{*}{$\begin{array}{l}\text { Average } \\
\text { mean }\end{array}$} & \multirow{2}{*}{$\begin{array}{l}\text { Standard } \\
\text { deviation }\end{array}$} & \multirow{2}{*}{$\begin{array}{c}\text { Standard } \\
\text { Error of } \\
\text { Mean }\end{array}$} & \multicolumn{2}{|c|}{$\begin{array}{c}95 \% \text { Confidence } \\
\text { Interval of Difference }\end{array}$} & & & \\
\hline- & & & & $\begin{array}{l}\text { Lower } \\
\text { Limit }\end{array}$ & Upper Limit & & & \\
\hline Attitude Toward & 5.154 & 4.862 & 1.349 & 2.216 & 8.092 & 3.822 & 12 & 0.002 \\
\hline
\end{tabular}

(3)Pearson product moment correlation analysis:

The time the students of the Experimental Group spent reading the teaching materials of Junyi Academy during the experimental instruction is shown in Table 5.

Table 5. The Time the Students of the Experimental Group Spent in Using Junyi Academy at Home

\begin{tabular}{|c|c|c|c|}
\hline Student No. & Time of Using (Minute) & Student No. & Time of Using (Minute) \\
\hline 70405 & 185 & 70802 & 420 \\
\hline 70411 & 108 & 70807 & 236 \\
\hline 70413 & 459 & 70809 & 454 \\
\hline 70426 & 193 & 70816 & 397 \\
\hline 70427 & 541 & 70827 & 355 \\
\hline 70437 & 180 & 71315 & 268 \\
\hline 70439 & 155 & & \\
\hline
\end{tabular}

The results of the Pearson product moment correlation analysis of the scores the students of the Experimental Group obtained in the behavioral attitude scale and the time they spent in studying on Junyi Academy are shown in Table 6.

Table 6. Abstract of the Pearson Correlation of the Behavioral Attitude and Learning Time of the Students of the Experimental Group

\begin{tabular}{|c|c|}
\hline & Learning Time \\
\hline Pearson Correlation & 0.325 \\
\hline Significance (two-tailed) & 0.047 \\
\hline Quantity & 13 \\
\hline Degree of Correlation & Low level of correlation \\
\hline
\end{tabular}

According to Table 6, the two-tailed $p$ value of the scores the students of the Experimental Group obtained in the behavioral attitude scale and the time they spent in studying on Junyi Academy was "0.047". This indicates that there was significant difference in the behavioral attitude of the students of the Experimental Group towards Junyi Academy and in using the platform to study the designated unit "Scientific Signs". But in the Pearson correlation analysis, the relevant value was "0.325", indicating a low level of correlation. The researcher believe that the students who obtained a high score in behavioral attitude were willing to increase the time of after-class learning and spend more time and energy on mathematical learning when they were filling the scale. But after all, the electronic games today are so tempting that students tend to fail to resist the temptation if they connect their computers with the Internet. In comparison, the learning platform may not be so attractive to them. Therefore, the level of correlation between behavioral attitude and learning time was low. According to the research results, there was significant difference in the attitude toward using and after-class learning before and after the remedial instruction based on the combination of Junyi Academy and mathematics. Moreover, the mean of the scale after the instruction was higher than that before the instruction.

\section{CONCLUSION}

This study aims to offer courses to a large number of online learners through MOOCs. By connecting the computer with Junyi Academy, learners will no longer be confined to a specific space for learning. This will improve the existing remedial instruction of mathematics, for it will make learning more customized and adaptive and contribute to more feasible remedial instruction. After the students of the Experimental Group received the experimental instruction, this study came to the following conclusions: 1) The students showed a more positive attitude after the remedial instruction based on Junyi Academy; 2) The students became more willing to study after the remedial instruction based on Junyi Academy; 3) There was significant difference between the learning time and attitude towards the remedial instruction.

\section{REFERENCES}

[1] Wu, C.M.(2015). The Study of Evaluating Remedial Instruction Program in Primary Mathematics Area Assisted by Flipped Classroom: An Example of the Fourth Grade Course. Master's Thesis, Department of Information Management, Nanhua University 
[2] Lin, C.P. (1997). Guidance for Learning: Theory and Practice. Taipei: Wu Nan Books.

[3] Huang, L.P. (2011). The Information Education Environment Based on the Basic Structure of Cloud Computing. Master's Thesis, Department and Graduate Institute of Information Management, Yu Da University of Science and Technology.

[4] Liu, T.Y. (2014). Integrating Multi-media and E-learning Platform to the Remedy Teaching for Mathematic: Taking "Pythagorean Theorem" in Junior High School as an Example. Master's Thesis, Department and Graduate Institute of Information Management, Yu Da University of Science and Technology.

[5] Tsai, Y.S. (2012). An Action Research of ARCS Motivation Strategies Embedded in Mathematics Remedial Instruction on Students' Learning Motivation and Learning Achievement. Master's Thesis, Graduate Institute of Science Education, National Changhua University of Education.

[6] Davis, F. D., Perceived usefulness, perceived ease of use, and user acceptance of information technology, MIS Quarterly, Vol. 13, No. 3, pp. 319-340, 1989.

[7] Paulson, F. L., Paulson, P. R. and Meyer, C. A., What makes a portfolio a portfolio?, Educational Leadership, Vol.48, No.5, pp. 60-63, 1991.

[8] Hair, J. F., Black, W. C., Babin, B. J., Anderson, R. E., and Tatham, R. L., Multivariate data analysis (6th ed.), New Jersey: Prentice-Hall, p.128, 2006.

[9] Harman, Harry Horace, Modern factor analysis, University Of Chicago Press., Chicago, 1976.

[10] Khan, B., Web-based instruction (WBI): What is it and why is it? In B. H. Khan (Ed.), Web-based instruction (pp.518). Englewood Cliffs, NJ: Educational Technology Publications, 1997.

[11] Malhotra,Y. and Galletta, D. F., "Extending the technology acceptance model to account for social influence: Theoretical bases and empirical validation," Proceedings of the Thirty-second Hawaii International Conference on System Sciences, 1999.

[12] Nunnally, J.C., Psychometric theory. Tata McGraw-Hill Education, 1978.

[13] Sanders, M. E., Web-based portfolios for technology education: A personal case study. The Journal of Technology Studies, Vol. 26, No. 1, pp. 11-18, 2000.

[14] Sharp, J.E., Using portfolios in the classroom. Proceedings of Frontiers in Education Conference, 1, 272-279, 1997.

[15] Spitzer, W., and Wedding, K., LabNet: An international electronic community for professional development. Computers and Education, Vol.24, No.3, pp.247-255, 1995.

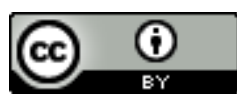

This work is licensed under a Creative Commons Attribution 4.0 International License. 